\title{
ANÁLISE DAS INFLUÊNCIAS DO CLIMA E DA CULTURA ORGANIZACIONAL DENTRO DE UMA ORGANIZAÇÃo QUE DÁ APOIO A PROPRIETÁRIOS DE MICRO E PEQUENAS EMPRESAS NA CIDADE DE SERRA TALHADA/PE
}

Renata do Nascimento Barbosa*

Leonardo Rodrigues Ferreira**

\section{RESUMO}

O presente estudo tem por finalidade analisar as influências do clima e da cultura organizacional dentro de uma instituição que apoia as pequenas empresas. Poder-se-á evidenciar as teorias administrativas que versam sobre o tema. Como material e métodos foram utilizadas livros, revistas especializadas e consultas a sites técnicos. Trata-se de uma pesquisa descritiva com uma abordagem qualitativa, em que foi adotada a entrevista direta com o gestor da unidade, o qual é a peça fundamental quando avaliamos clima e cultura organizacional. Quanto aos resultados conseguiu-se diagnosticar os problemas, principalmente no tocante ao relacionado com a temática (clima e cultura organizacional) e foi realizado um plano estratégico com a utilização da ferramenta de SWOT.

PALAVRAS-CHAVE: Organização, Cultura, Clima.

\begin{abstract}
This study aims to analyze the influence of climate and organizational culture within an institution that supports small businesses. It may be possible the administrative theories that deal with the subject. As material and methods were used books, specialized magazines and queries to technical sites. It is a descriptive research with a qualitative approach, in which the direct interview with the unit manager was adopted, which is the fundamental piece when evaluating climate and organizational culture. As for the results, it was possible to diagnose the problems, especially in relation to the theme (climate and organizational culture), a strategic plan was carried out using the SWOT tool.
\end{abstract}

KEY WORDS: Organization, Culture, Climate.

* Graduada em Administração pela UFRPE/UAST.

** Administrador e Contador; Especialista e Mestre em Administração; Professor Assistente da UFRPE/UAST. 


\section{INTRODUÇÃO}

A maioria das pessoas passa grande parte da vida trabalhando, e com isso são criados laços entre todos os trabalhadores; dessa forma, percebe-se em cada empresa um tipo de cultura diferente, que na maioria das vezes é passada do proprietário do estabelecimento para os seus funcionários, partindo dos níveis hierárquicos superiores para os inferiores. Chiavenato (1999) conceitua cultura organizacional como algo que toda organização tem em sua essência, mostrando como ela age, desde a forma como seus gestores a administram até a forma como tratam seus funcionários, deixando um registro de sua identidade. Com isso, percebe-se a vinculação entre a cultura organizacional e o clima organizacional da empresa, pois o clima é definido a partir da forma que é gerida a cultura. Por exemplo, se a empresa tem em sua cultura tratar bem os funcionários, incentivá-los, ajudá-los, isso fará com que o seu clima seja bom, pois os funcionários se sentirão motivados e felizes com o que fazem.

São muitas as formas como o ser humano se comporta, decide, trata os clientes e administra, e com isso o clima organizacional pode mudar constantemente, dependendo de fatores internos e externos. Nos dias de hoje as empresas têm se qualificado cada vez mais para lidar com a administração de pessoas, sabendo que pessoas motivadas e felizes podem gerar mais resultados positivos.

Partindo desse preceito, pretende-se nesse trabalho explorar as teorias administrativas de clima e cultura organizacional, para que se possa ter um maior respaldo sobre o tema e tentar descobrir lacunas sobre como a empresa trata o seu clima e cultura organizacional. $\mathrm{O}$ objetivo geral deste estudo é buscar soluções sobre os problemas gerados pelo mau gerenciamento do clima e da cultura da empresa, e partindo disso, conseguir obter soluções específicas para cada problema, mostrando assim a importância de uma empresa com um clima organizacional bem definido. Para este estudo, foi utilizado um questionário que foi respondido pelos envolvidos na empresa, a fim de descobrir os maiores problemas e como poder solucioná-los, além de uma análise SWOT do ambiente interno da empresa, que ajudou no estabelecimento de objetivos específicos para esse estudo, como os pontos fortes e fracos do clima e da cultura da empresa, e as ameaças que eles podem causar como também as oportunidades que a empresa obtém a partir do solucionar desses problemas. Sendo assim, tentar-se-á aqui explanar os problemas encontrados a partir do clima e cultura organizacional 
da empresa e com isso tentar solucioná-los a partir de técnicas já conhecidas pelos administradores, a fim de melhorar o desempenho e resultados da organização.

\section{REFERENCIAL TEÓRICO}

O seguinte trabalho irá abordar o conceito de clima e cultura organizacional, tentando levantar ideias para que se melhorem esses temas dentro da organização, trazendo resultados mais satisfatórios para os envolvidos.

\section{Cultura Organizacional}

Segundo Chiavenato (1999), a Cultura Organizacional é a reunião das partes que formam hábitos, normas, costumes, crenças estabelecidas, atitudes e experiências compartilhadas por todos os colaboradores da organização. Geralmente, tem representação nos níveis superiores de uma organização, onde o proprietário traz consigo uma identidade cultural que por muitas vezes acaba empregando na empresa. Dessa forma ele passa esse seu modo para os responsáveis na empresa, fazendo com que sua identidade influencie bastante a tomada de decisão dentro da organização. Isso não acontece apenas de proprietário para gerentes, mas também de gerentes influenciarem seus subordinados.

Nas empresas de pequeno porte essa prática é bem mais visível, pois o proprietário tem o controle de praticamente tudo, influenciando seus funcionários e deixando a empresa cada vez mais com sua cara, ou seja, tornando os aspectos da empresa como os seus. É importante uma empresa preservar a sua identidade, pois mostra como ela age para todos os seus stakeholders, afinal, toda empresa tem que ter sua identidade diferenciada para ocupar seu lugar no mercado. Além disso, ela pode ajudar a diminuir as incertezas dos funcionários quando ao trabalho, mostrando as formas como as tarefas devem ser realizadas. O pilar da cultura de uma organização é ditado da forma como são feitos os negócios, além da forma como são tratados seus colaboradores, funcionários e clientes, a forma de gerir um escritório, e a liberdade dada a cada funcionário. De forma mais resumida, a cultura organizacional aborda conceitos de crença, moral, costume, conhecimento e hábitos, dentre outros. Uma forma de auxílio na hora de definir a cultura organizacional é utilizando-se da Matriz SWOT, 
que é uma análise que ajuda a obter respostas sobre o ambiente interno e externo de uma empresa, identifica as fraquezas, os pontos fortes, oportunidades e ameaças que ela pode enfrentar; assim a empresa pode colher as informações dos seus funcionários, fazendo com que contribuam para a definição da cultura e dos valores. Segue uma breve descrição sobre a análise de SWOT.

\section{Análise SWOT}

A matriz SWOT foi criada para desenvolver os pontos fracos e fortes de uma empresa, como também de suas oportunidades e ameaças, utilizando de analises do ambiente externo e interno. Na maioria das vezes a análise da matriz SWOT é feita para traçar uma estratégia competitiva, mas como é visto na cultura organizacional, ela serve para muitas coisas além disso, podendo auxiliar também na descoberta da cultura e dos valores da empresa. Segue modelo abaixo:

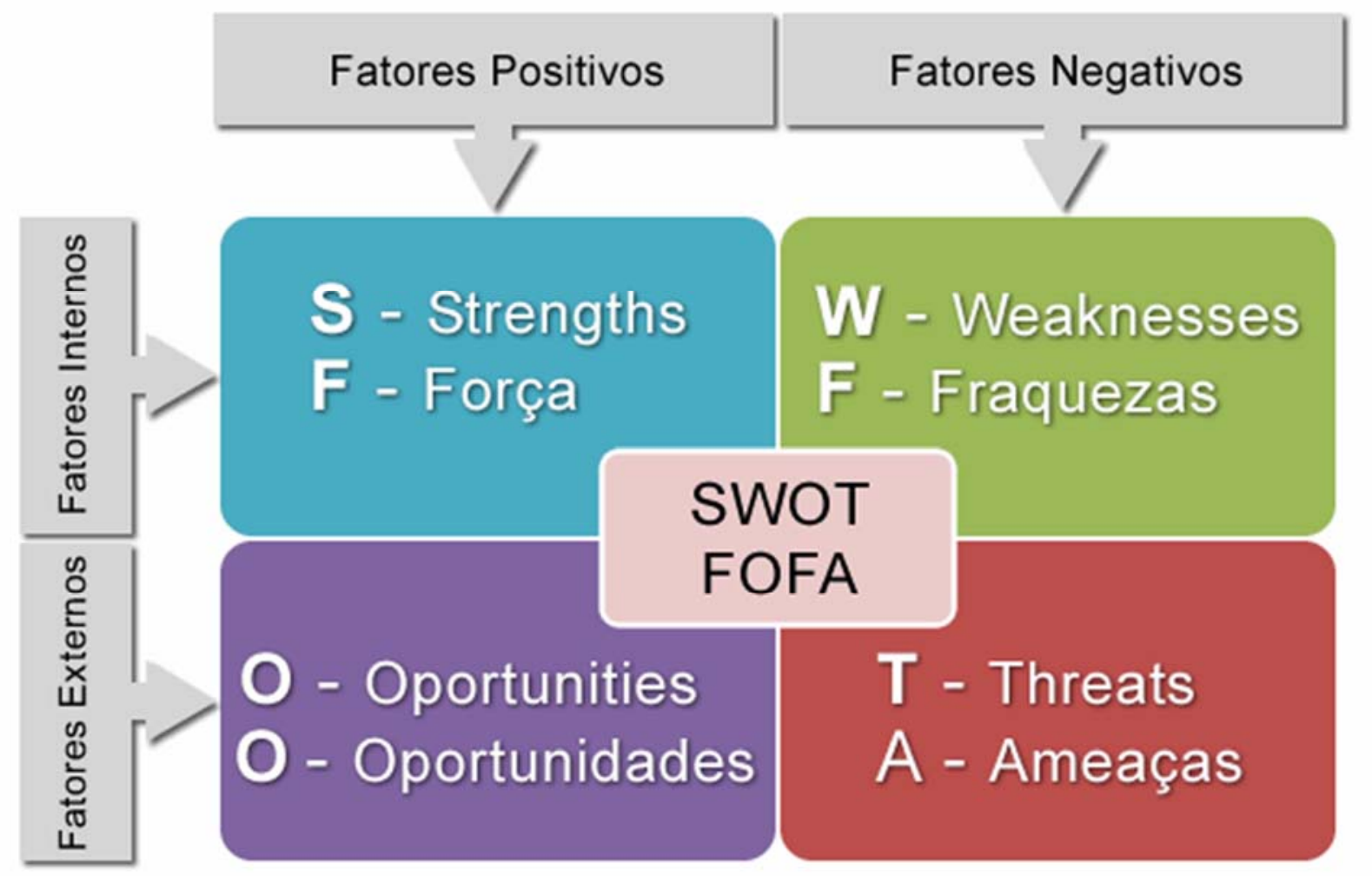

Figura 1 - Exemplo de Matriz SWOT.

Fonte: TREASY (2016) 
Segundo Shahiret al. (2008), o termo SWOT tem origem no inglês e é uma sigla de forças (strengths) e fraquezas (weaknesses), ameaças (threats) e oportunidades (opportunities), também conhecida como F.O.F.A., a qual é acrônimo das mesmas palavras na língua portuguesa, embora reordenadas diferentemente.

Strenghts (forças) - Estabelece os pontos fortes da organização considerando os clientes externos e internos. Para determinar os pontos fortes, devem ser identificadas as vantagens que dão destaque à organização, além dos motivos que a elegem como escolha dos clientes em detrimento aos concorrentes (WEIHRICH, 1982).

Weaknesses (fraquezas) - Segundo Araújo (2010), correspondem aos pontos mais vulneráveis da empresa em comparação aos mesmos pontos dos seus concorrentes atuais ou em potencial. As forças e fraquezas são determinadas pela posição atual da empresa e estão relacionadas a fatores internos da organização. No entanto, deve-se atentar que muitas vezes as forças e fraquezas se confundem. Além disso, uma força atual pode se transformar em fraqueza no futuro.

Opportunities (oportunidades) - O crescimento da organização depende da percepção das oportunidades que podem estar presentes, por conta de mudanças tecnológicas, das preferências dos consumidores, concorrência pela melhor oferta de qualidade nos serviços, políticas governamentais e novos padrões sociais (TEIXEIRA, et al., 2011).

Threats (ameaças) - São compostas por desafios decorrentes de fatores externos que apresentam ameaças à sobrevivência da empresa, como, por exemplo, as novas leis e medidas regulatórias, as introduções de novas tecnologias, as mudanças nos padrões de consumo, o lançamento de produtos, a redução no poder de compra dos consumidores, dentre outros fatores. Todos estes fatores estão fora do controle da organização e podem vir a prejudicar o desempenho da empresa (WEIHRICH, 1982). Segue uma breve descrição sobre o clima organizacional.

\section{Clima Organizacional}


Segundo Bergamini e Coda (1997, p. 98), "Clima Organizacional nada mais é do que indicador do nível de satisfação (ou de insatisfação) experimentado pelos empregados no trabalho". Ou seja, o clima é algo que está mudando constantemente, de acordo com atitudes vivenciadas no trabalho, dessa forma, nós somos os agentes do clima de uma organização.

O clima organizacional pode afetar positiva ou negativamente o comportamento das pessoas dentro de uma empresa, por isso é importante realizar um estudo sobre esse clima a fim de descobrir se é necessário mantê-lo ou modificá-lo, pois tanto a organização quanto as pessoas mudam frequentemente. E o estudo do clima pode gerir essas mudanças além de auxiliar na capacidade da organização de atrair e reter talentos. Segundo Oliveira (1995, p. 70), “As pesquisas de clima são feitas geralmente por meio de questionários e/ou entrevistas, tentando-se obter as opiniões dos empregados acerca de vários itens sobre os quais a empresa tem interesse em saber o que seu pessoal pensa”. Kahale (2003, p. 1) comenta que uma pesquisa de clima organizacional é um instrumento voltado para análise do ambiente interno a partir do levantamento de suas necessidades. Objetiva mapear ou retratar os aspectos críticos que configuram o momento motivacional dos funcionários da empresa por meio da apuração de seus pontos fortes, deficiências, expectativas e aspirações.

Nos tempos atuais, o estudo do clima organizacional é de extrema importância porque há tendência de maior cuidado com pessoas, com os seus colaboradores externos e principalmente os internos, aqueles que estão no dia a dia da empresa e que podem opinar de maneira satisfatória. Gestores se deram conta do grande valor que as pessoas têm para a organização, e a partir do estudo do estudo do ambiente interno, podem enfrentar efetivamente os focos de problemas, melhorando assim o clima. Segue um breve comentário sobre o organograma clássico.

\section{Organograma Clássico}

O organograma serve para se estruturar o pessoal dentro de uma organização, e por meio dele, é possível hieraquizá-la. Com isso, facilita-se o acesso a seu devido superior e inferior, pois, segundo Chiavenato (2000), a organização formal compõe-se de camadas hierárquicas ou níveis funcionais estabelecidos pelo Organograma e com ênfase nas funções e nas tarefas. Ainda pode ser definido como "diagrama da estrutura de uma organização, 
mostrando as funções, os departamentos ou as posições na organização, e como esses elementos se relacionam" (STONER e FREEMAN, 1999, p. 231).

Existem vários tipos de organograma, dos mais simples, como o diagrama clássico, até os mais complexos, como o circular e o matricial. O organograma tem como intuito o funcionário saber o seu lugar na empresa e a quem deve atender. É comum em várias empresas que têm vários gestores de setores diferentes mandarem uma mesma pessoa realizar tarefas diversas, criando dificuldades na comunicação.

Exemplo de organograma vertical, clássico ou formal:

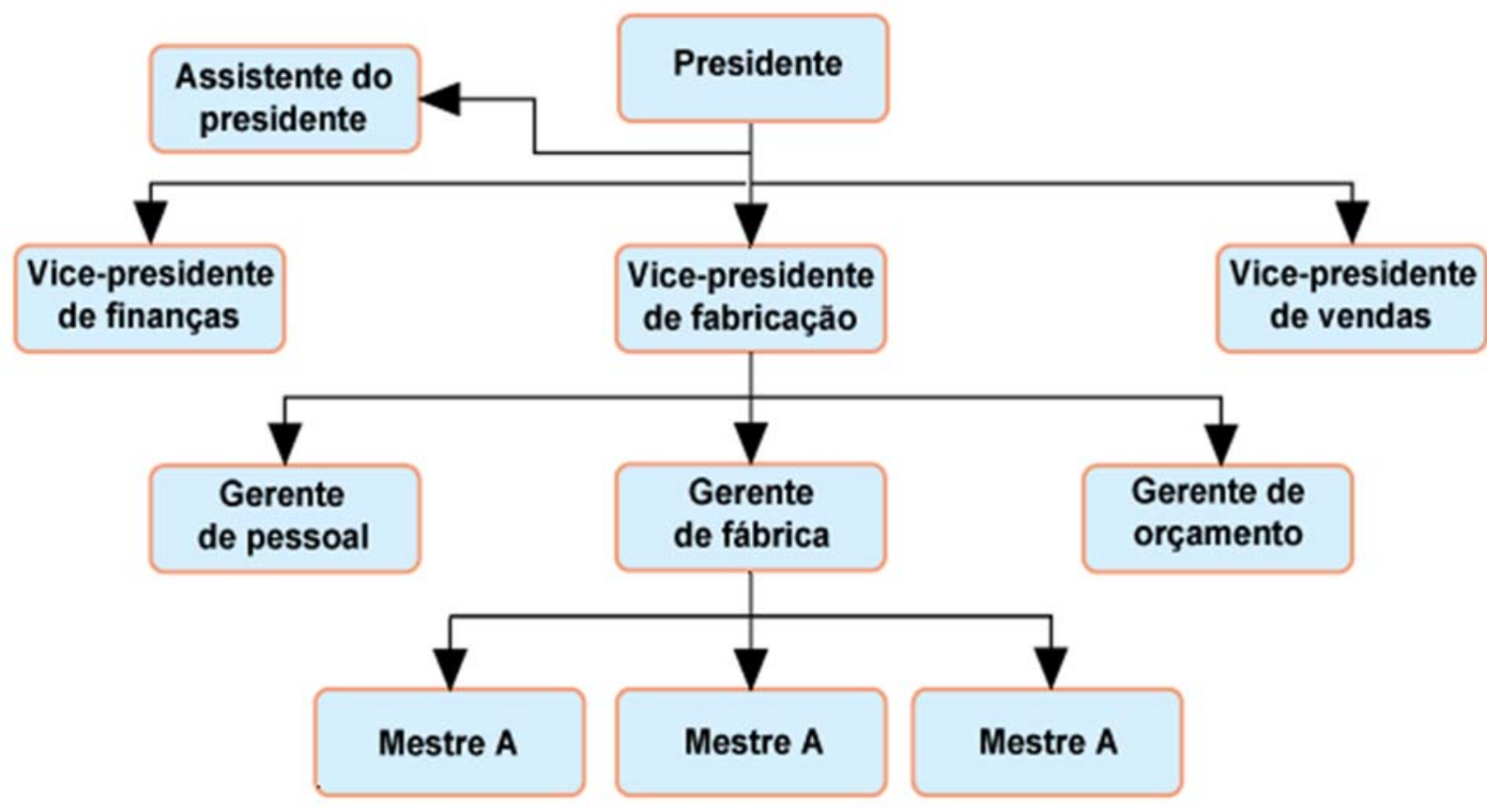

Figura 2 - Exemplo de Diagrama Organizacional de uma Empresa.

Fonte: LUZ (2016)

A figura 2 é um exemplo de organograma clássico e simples, de forma vertical e funcional, demonstrando verticalmente as funções de cada pessoa da empresa, e classificandose de cima para baixo, onde o topo é cargo superior e os mais baixos são os cargos inferiores. 
O presente trabalho foi realizado através de estudos por livros e internet, levantando bibliograficamente conceitos administrativos que possibilitassem um entendimento maior sobre clima e cultura organizacional. $\mathrm{O}$ trabalho trata-se de uma pesquisa descritiva com uma abordagem qualitativa, sabendo-se que, segundo Barros e Lehfeld (2007), dentro da pesquisa descritiva realizam-se o estudo, a análise, o registro e a interpretação dos fatos do mundo físico sem a interferência do pesquisador. São exemplos de pesquisa descritiva as pesquisas mercadológicas e de opinião. Esse tipo de pesquisa tem por finalidade observar, analisar e registrar os fatos, para que dessa forma se possa descobrir o problema e procurar possíveis soluções. A pesquisa pode ser entendida como um estudo de caso onde, após a coleta de dados, é realizada uma análise das relações entre as variáveis para uma posterior determinação dos efeitos resultantes em uma empresa, sistema de produção ou produto (PEROVANO, 2014).

No âmbito da pesquisa qualitativa, existe uma relação entre a realidade e o pesquisador; é feita de maneira descritiva e utiliza-se o método indutivo, tendo foco no processo das coisas. É realizada através de um questionário para entrevistar os envolvidos, tentando obter resultados para os quesitos da pesquisa. A pesquisa qualitativa não se preocupa com representatividade numérica, mas, sim, com o aprofundamento da compreensão de um grupo social, de uma organização, etc. Algumas características da pesquisa qualitativa são: objetivação do fenômeno, hierarquização das ações de descrever, compreender e explicar as relações entre a realidade e a teoria, buscando resoluções para suas peculiaridades. Para os que adotam a abordagem qualitativa opõem-se ao pressuposto que defende um modelo único de pesquisa para todas as ciências, já que as ciências sociais têm sua especificidade, o que pressupõe uma metodologia própria. Assim, os pesquisadores qualitativos recusam o modelo positivista aplicado ao estudo da vida social, uma vez que o pesquisador não pode fazer julgamentos nem permitir que seus preconceitos e crenças contaminem a pesquisa (GOLDENBERG, 1997, p. 34).

Dessa forma, o nosso trabalho se utilizou de uma pesquisa semiestruturada com cada classe da unidade em questão nesse trabalho. A empresa em questão é uma unidade de uma empresa de grande porte e está localizada na cidade de Serra Talhada (PE), possui quinze funcionários divididos entre gerente, analistas, técnicos, terceirizados e estagiários. Dessa 
forma, realizou-se uma entrevista com o gerente, um analista, um técnico, um estagiário e um terceirizado, para que assim pudéssemos ter um respaldo maior sobre os conhecimentos dos envolvidos na empresa, e como se sentem cada um deles a respeito do clima e cultura da organização, com o objetivo de descobrir os problemas encontrados a partir desse tema, e possíveis soluções para o mesmo. Dessa forma, os dados coletados foram decorridos no trabalho de forma que se pudesse colher as informações necessárias para uma intervenção efetiva na empresa.

\section{RESULTADOS E DISCUSSÕES (PROPOSTA DE INTERVENÇÃO)}

Depois de realizada uma análise visual e prática e algumas entrevistas na empresa, se pôde levantar uma proposta de intervenção levando em consideração os conceitos teóricos relacionados ao clima organizacional. A partir dessas teorias administrativas conseguiu-se diagnosticar o problema e realizar um plano estratégico para expor esses pontos. Detectamos que a falta de um organograma para cada unidade contribuía para agravar o problema de comunicação. A utilização de uma análise da matriz SWOT permite encontrar os pontos fortes e fracos da cultura e do clima organizacional. Foram feitas entrevistas com cada parte da unidade, para assim podermos ter um melhor entendimento de como cada uma se posiciona em relação ao tema. Seguem os resultados:

\section{1) Organograma}




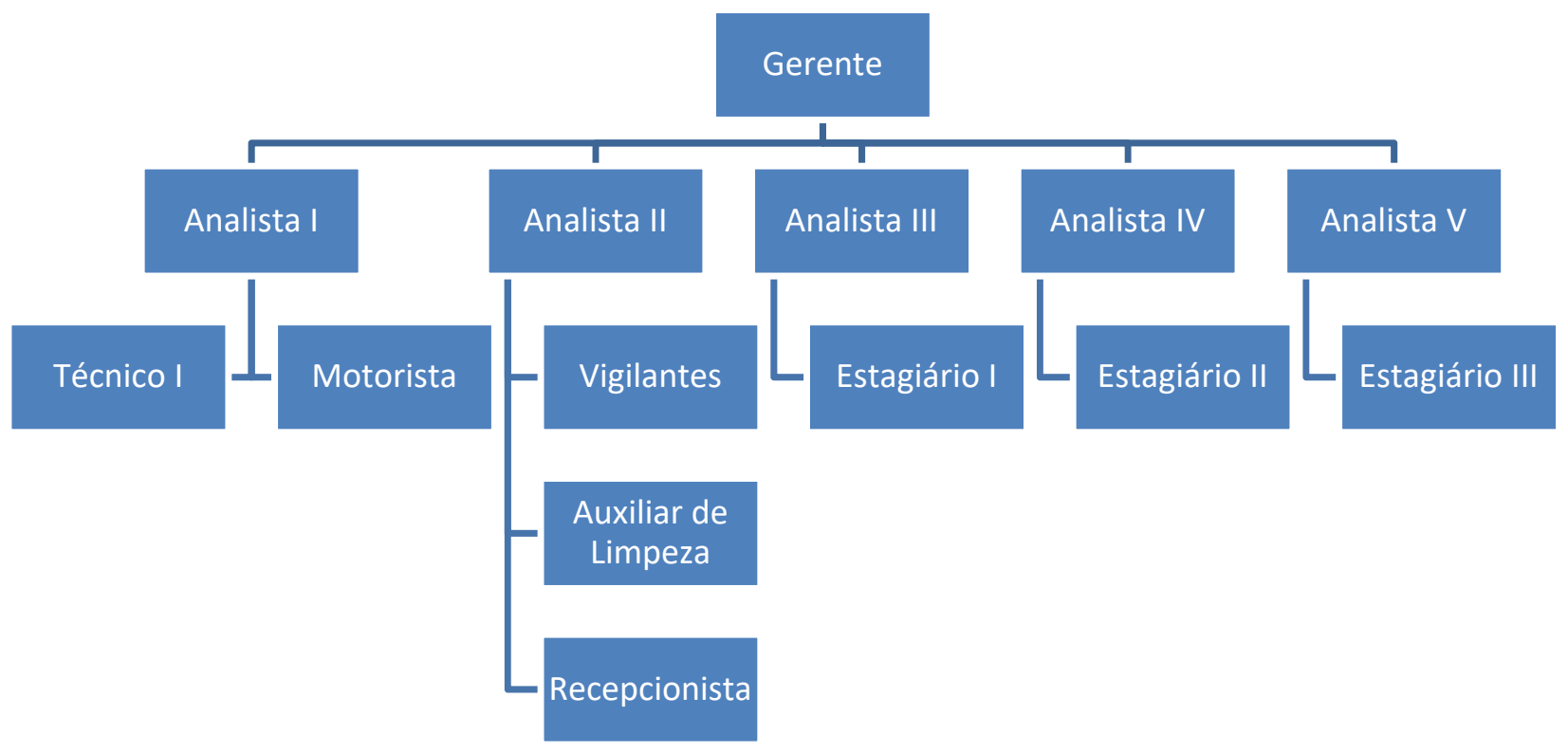

Figura 3 - Exemplo de Diagrama Organizacional da Empresa.

Fonte: Autor (2016)

Como se pôde ver na figura 2, o organograma ideal para a unidade seria esse, em que o gerente se situa acima de todos, seguido dos analistas. Dessa forma as pessoas se reportariam de melhor forma a um devido analista, e esse analista seria o responsável por essas pessoas, mostrando assim mais clareza na hora de se obedecer a um pedido de um superior, e de o gerente conseguir controlar cada pessoa da unidade.

\section{2) Resultado das Entrevistas}

Foram realizadas cinco entrevistas iguais com cada parte da unidade, para poder ter um respaldo maior sobre a posição de cada área da empresa, realizada da seguinte forma: entrevista com o gerente, com um analista, com um técnico, com um estagiário e com um terceirizado.

2.1) De acordo com a entrevista com o gerente da unidade, foram colhidas as seguintes respostas: 
Ao ser perguntado o que entende por cultura e clima organizacional, foi respondido que: "Entendo que cultura e clima organizacional são coisas fundamentais para qualquer organização. Culturas vêm da identidade de cada um e é algo que se traz junto de si, passando para seus subordinados, é como uma espécie de marca da pessoa. Clima, por outro lado, é o ambiente emocional da organização. Uma empresa com um bom clima organizacional produz melhor, pois as pessoas vão estar conectadas entre si, mostrando bons resultados”. Com isso, percebe-se que o gerente tem uma boa visão sobre os conceitos administrativos de clima e cultura organizacional, tendendo a utilizá-los para um melhor interagir da unidade.

Quando perguntado se sua cultura pessoal interfere nas atividades da empresa, foi respondido o seguinte: “Acredito que sim. É inevitável os gestores de organizações deixarem marcas nos seus funcionários, pois é algo que temos dentro de nós e que às vezes acaba acontecendo sem nem ao menos percebermos”. Assim, vimos que ele realmente sabe que influencia seus subordinados com suas próprias peculiaridades.

A respeito dos seus costumes, foi perguntado o que ele acha que poderia ser mudado dentro da organização, e foi dito que: "Acredito que poderia me relacionar melhor com meus subordinados. Claro que possuímos uma relação muito boa, mas não há nada que não possa ser melhorado. Por viajar muito, acredito que não participo com êxito das atividades internas dos meus colaboradores. Tenho que me posicionar como amigo, além de gerente”. Dessa forma, vimos que o gerente tenta melhorar seu relacionamento com os funcionários. Ele sabe que é importante manter um bom relacionamento com todos, mas é importante ressaltar que ele deve saber a hora de ser amigo e ser chefe.

Ao ser perguntado se a empresa tem um clima organizacional agradável, foi respondido que: "Sim, a empresa possui um ótimo clima organizacional, todos se dão muito bem, o que faz com que a gente consiga andar bem com a unidade”. Vemos com isso que ele acha avalia como bom o clima organizacional e, por isso, a unidade segue sem problemas.

Ainda a respeito do clima organizacional, foi perguntado quais os seus pontos fortes e fracos. A resposta foi a seguinte: "Como ponto forte, somos bem unidos, tanto na vida profissional quanto pessoal. Por ser uma unidade pequena, todos os funcionários se 
conhecem e convivem bem, e com isso temos uma ótima relação, propiciando um bom desenvolvimento. Como ponto fraco, acredito que, por termos esse bom relacionamento próximo, fica um pouco difícil na hora que vêm más notícias da sede para algum funcionário”. Percebe-se aqui que o gestor possui amizade com boa parte da organização, o que dificulta na hora de tomar medidas severas em relação a algum funcionário.

2.2) De acordo com a entrevista com uma analista da unidade, foram colhidas as seguintes respostas:

Ao ser perguntada o que se entende por cultura e clima organizacional, foi respondido que: “Bom, eu consigo entender que cultura é a forma de trabalho, o jeito que se tem dentro da empresa na hora de realizar as tarefas. Clima é o meio de convivência entre os funcionários”. Com isso, é percebido que a analista tem um pequeno entendimento do assunto, mas que este poderia ser mais bem esclarecido.

Quando questionada se sua cultura pessoal interfere nas atividades da empresa, foi respondido o seguinte: "Não, eu não me imponho em relação às atividades da empresa. Acredito que sou reservada e não possuo influência significativa sobre a cultura dessa unidade, claro que todos contribuímos um pouco para essa cultura, mas acho que minha é parte é pouco significativa”. Assim, vemos que ela não crê que sua cultura pessoal interfira na empresa, mesmo sabendo que todos podem influenciar e serem influenciados em uma cultura organizacional.

A respeito dos seus costumes, foi perguntado o que ela acha que poderia ser mudado dentro da organização, e foi dito que: “Bom, acho que eu poderia fazer mais pela própria empresa, me impor mais. Sou muito reservada e acredito que isso dificulta um pouco até o relacionamento com meus amigos, por isso, acho que devo me propor a interagir mais com minha equipe”. Dessa forma, foi visto que a analista se sente meio retraída com a equipe, não sente que faz parte totalmente da equipe, ao contrário do que o gestor achava.

Ao ser perguntado se a empresa tem um clima organizacional agradável, foi respondido que: "Com certeza, a empresa tem um ótimo clima organizacional, todos são muito amigos e receptivos, acredito que é um diferencial dessa unidade”. Assim, é 
perceptível que ela acha que a organização tem um bom clima, e que isso é um diferencial para eles.

A respeito do clima organizacional, foram questionados quais os seus pontos fortes e fracos. A resposta: "Ponto forte, acho que deve ser essa boa receptividade da equipe, o que gera uma fácil adaptação para quem é novo na empresa, muitas vezes ajuda muito os estagiários que são trocados com mais frequência, e não acredito que possua pontos negativos”. Percebe-se aqui que a analista acredita que o clima só possui pontos positivos, por conta da receptividade de seus companheiros, sem possuir nenhum ponto negativo, na sua visão.

2.3) Em entrevista com uma técnica da unidade colhemos as seguintes respostas:

Ao ser perguntada o que se entende por cultura e clima organizacional, foi respondido que: "Eu acho que cultura e clima são coisas relacionadas, e que uma é dependente da outra, pois se a cultura for boa, o clima também será”. Com isso, é percebido que a técnica não tem uma boa noção sobre os dois conceitos.

Quando perguntada se sua cultura pessoal interfere nas atividades da empresa, foi respondido que: “Acredito que possa, sim, interferir, porque cada um de nós traz traços da vida, e que colocamos em tudo o que fazemos, por isso essa unidade é do jeito que nós a fazemos”. Assim, vemos que ela realmente acha que sua cultura pessoal possa interferir, como também a dos seus colegas.

A respeito dos seus costumes, foi perguntado o que ela acha que poderia ser mudado dentro da organização, e foi dito que: “Nada, não preciso mudar em nada os meus costumes dentro da organização, pois acho que não estão influenciando negativamente em nada aqui dentro”. Dessa forma, vemos que a técnica não acredita que seus costumes pessoais estão interferindo em algo na empresa.

Ao ser perguntada se a empresa tem um clima organizacional agradável, foi respondido que: "Sim, somos uma boa equipe, bem unidos tanto dentro como fora da empresa”. Assim, a técnica acredita que a equipe possui uma boa interação, inclusive no âmbito pessoal. 
A respeito do clima organizacional e de seus pontos fortes e fracos, a resposta foi a seguinte: "Temos como ponto forte a nossa união, que é fundamental para as atividades da unidade, e como ponto fraco acredito que interação do nosso gerente, pois ele viaja bastante e por isso acaba muitas vezes deixando de participar das atividades internas, deixando o laço um роисо "frouxo"”. Percebe-se aqui que a técnica acredita na união da empresa e que acredita ser negativo o fato de o gestor sempre viajar, mesmo que seja por ordens superiores, pois assim deixa o laço entre eles mais fraco.

2.4) De acordo com a entrevista com um estagiário da unidade, foram colhidas as seguintes respostas:

Ao ser perguntado o que se entende por cultura e clima organizacional, foi respondido que: "Cultura organizacional vem da cultura de cada funcionário ou geralmente do gestor, que vai passando para cada funcionário, formando assim a identidade da empresa. Clima é a relação entre todos da empresa, e como as coisas acontecem por conta disso". Percebemos que o estagiário possui grande noção dos conceitos de clima e cultura organizacional.

Quando perguntado se sua cultura pessoal interfere nas atividades da empresa, foi respondido que: "Não, muito pelo contrário, acredito que somos influenciados pela cultura do gestor ou até mesmo ele é influenciado pela cultura dos seus superiores e, assim, acaba passando para cada um de nós”. Assim, vemos que ele não acredita que influencia na cultura organizacional, e que é influenciado pelos demais.

A respeito dos seus costumes, foi perguntado o que ele acha que poderia ser mudado dentro da organização, e foi dito que: "Não, pois meus costumes não influenciam em nada na empresa, como já disse na pergunta anterior, acredito que nós, subordinados, somos mais influenciados do que influenciamos em algo”. Assim, vemos que o estagiário acredita na influência externa sobre os subordinados.

Ao ser perguntado se a empresa tem um clima organizacional agradável, foi respondido que: “Mais ou menos, acredito que poderia ser melhor”. Vemos assim que ele possui certo preconceito ao clima existente na empresa. 
A respeito do clima organizacional, sobre os seus pontos fortes e fracos, a resposta foi a seguinte: "Como ponto forte, a empresa possui um clima bom, mas entre os analistas, gerentes e técnicos, ou seja, entre o pessoal que é concursado e vinculado direto com Recife, e isso é bom de certa forma para eles. Já como ponto fraco, acredito que eles são pouco favoráveis aos subordinados, não temos muito direito de resposta e isso pode acabar prejudicando nos trabalhos desenvolvidos na organização”. Percebe-se aqui que o estagiário acredita que os subordinados como eles e os terceirizados não possuem muitos direitos na unidade.

2.5) De acordo com a entrevista com um terceirizado da unidade, foram colhidas as seguintes respostas:

Ao ser perguntado o que se entende por cultura e clima organizacional, foi respondido que: "Rapaz, eu não entendo muita coisa sobre isso não, mas acredito que seja o clima entre nós da unidade, né?”. Percebe-se aqui que o terceirizado não possui muito conhecimento da área.

Quando perguntado se sua cultura pessoal interfere nas atividades da empresa, foi respondido o seguinte: "Não, nós não nos envolvemos muito com as coisas da organização. Fazemos o que somos pagos para fazer, também não temos a oportunidade de interagir de forma que vá interferir em algo na empresa”. Assim, vemos que os terceirizados não possuem muita influência nas atividades-fim da empresa.

A respeito dos seus costumes, foi perguntado o que ele acha que poderia ser mudado dentro da organização. Foi dito que: “Nada, por não interferimos muito na hora das atividades deles, não temos no que interferir e nem mudar”. Dessa forma, vimos que ele acha que na sua posição não tem nada o que ser mudado.

Ao ser perguntado se a empresa tem um clima organizacional agradável, foi respondido: "Possui, sim. O clima é bom aqui dentro, mas é meio dividido, pois é como se existisse um tipo de clima com uma parte e com outra”. Dessa forma, vemos que a empresa está dividindo seu clima em duas partes, em relação à escala hierárquica, uma superior e outra inferior. 
A respeito dos seus pontos fortes e fracos, a resposta foi a seguinte: "Ponto forte é o clima organizacional, a boa receptividade dos superiores; são pessoas boas e que ajudam quando necessário. Como fraco, é a falta de comunicação em determinados momentos, em que temos muitos chefes e as vezes não sabemos quem realmente é o chefe principal”. Percebe-se assim uma falha de comunicação em relação às ordens de chefe para subordinado, pois como existem muitos analistas na unidade, o terceirizado não sabe a quem obedecer primeiramente, por isso, a importância de um organograma.

Ao se fazer uma análise das respostas colhidas, percebemos que a empresa possui uma desigualdade na sua estrutura, os cargos mais altos pensam que o clima da empresa está bem desenvolvido, já as classes mais baixas não se sentem satisfeitas com esse clima. Também se pode perceber que os estagiários e os terceirizados sentem-se sem voz dentro da empresa, sem poder opinar dentro da unidade. Sendo assim, a empresa acaba perdendo por não ouvir a opinião de todos, por isso se faz necessária uma análise do ambiente interno da empresa, para se poder melhorar o seu clima e incluir toda a equipe em um só grupo.

\section{3) Analise SWOT}

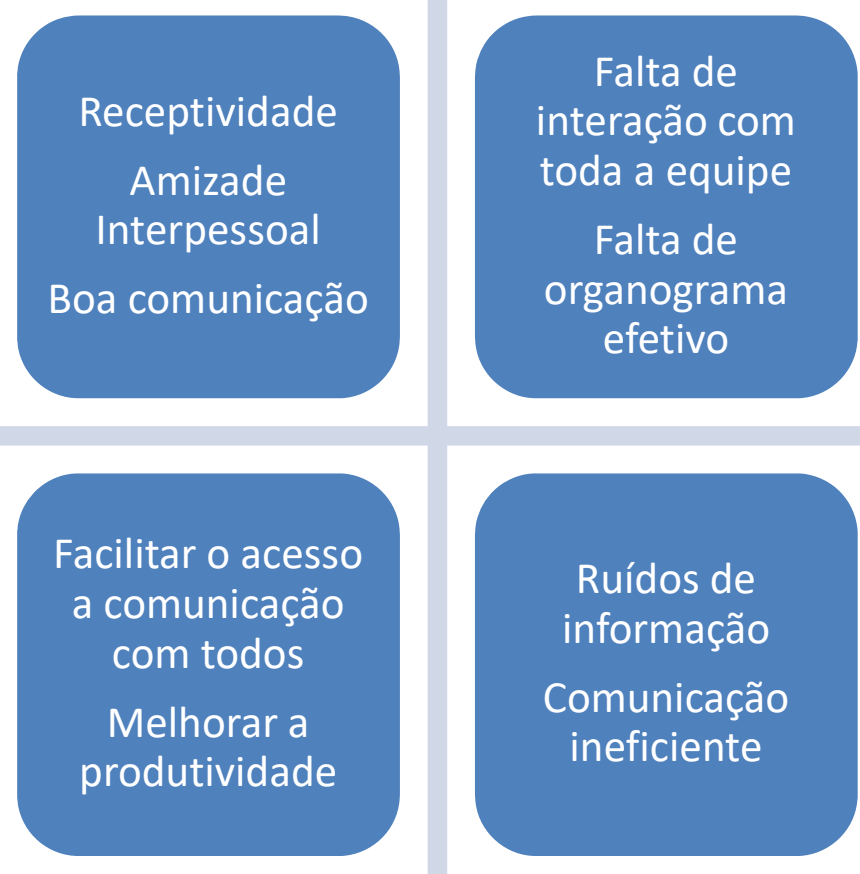

Figura 4 - Exemplo de Matriz SWOT da empresa. 
Fonte: Autor (2016)

Com a análise SWOT do ambiente interno da empresa, pôde-se constatar que podemos melhorar o clima organizacional. Ela já possui pontos fortes, como foi constatado a partir da entrevista, como a receptividade da equipe com novatos da empresa, a amizade que todos possuem além do trabalho e a boa comunicação da equipe. Como ponto fraco, a falta de interação com toda a equipe, muitas vezes se restringindo aos analistas da empresa, a falta de um organograma efetivo, que faz com que os subordinados se sintam perdidos ao receber ordens diferentes de analistas diferentes. A empresa tem a oportunidade de facilitar o acesso à informação com todos os colaboradores, pois com uma boa comunicação, certamente a produtividade aumentará. Como ameaças, a falta do organograma cria ruídos de informação, ou seja, um analista pede uma coisa, e outro pede outra coisa, fazendo com que o subordinado se sinta perdido, tentando fazer tudo ao mesmo tempo e obviamente deixando de realizar as atividades com mais eficiência.

\section{CONSIDERAÇÕES FINAIS}

No presente trabalho procurou-se estudar os efeitos do mau gerenciamento do clima e da cultura organizacional em uma unidade de uma empresa de grande porte localizada na cidade de Serra Talhada- PE, e que trabalha com a instrução de pequenos e médios empresários. Tentamos identificar os problemas que podem ser causadores desses fatores.

Todas as empresas têm sua cultura definida e diferenciada das demais, pois esta vem de cada proprietário que a repassa aos seus subordinados, imprimindo sua identidade na organização, e influenciando diretamente no dia a dia dos trabalhos. Um mau gerenciamento do clima organizacional pode causar problemas internos que se não forem bem esclarecidos podem se propagar externamente, trazendo grandes danos à organização. Por esse motivo, a organização em questão nesse trabalho foi estudada para que se proporcionem maneiras de trabalhar esses temas e procurar resolver os problemas causados por eles.

Nesse estudo, procurou-se mostrar como os problemas de um mau gerenciamento do clima e da cultura da empresa podem causar danos graves, e por isso deve ser tratado o mais rápido possível. A partir das entrevistas, verificou-se que a empresa possui um clima divido entre duas bases: os que ganham mais e os que ganham menos, além de ter suas tomadas de 
decisões muito centralizadas, por isso foi aplicada uma análise SWOT que possibilitou mostrar onde a empresa pode melhorar suas oportunidades e cuidar de suas ameaças, para que se descentralize mais e inclua todos os funcionários como um único grupo. Também foi importante a definição do organograma da empresa, pois possibilitou que os funcionários se localizem dentro da organização, facilitando as ordens a serem obedecidas e cada um sabendo em que lugar está lá dentro.

Para concluir, foi visto que o estudo aqui trabalhado cumpriu o que se pretendia, e pode servir como base para estudos e pesquisas sobre o tema, além de servir de contribuição para a referida empresa, caso possa e queira aplicar os devidos sistemas aqui propostos. Esperamos ter contribuído para que a empresa possa melhorar essa questão e solucionar todos os problemas que tenham e que possam vir a ter no que se refere ao clima e cultura organizacional, para dessa forma poder se destacar e servir de exemplo para os empresários que forem utilizar dos serviços prestados pela organização.

\section{REFERÊNCIAS}

ARAUJO, O. Análise SWOT (Strengths, Weaknesses, Opportunities, Threats) ou (Forças, Fraquezas, Oportunidades e Ameaças). Disponível em: < http://www.dearaujo.ecn.br/cgibin/asp/analiseSwot.asp.> Acesso em: 05 Out 2016.

BARROS, Aidil Jesus Paes de; LEHFELD, N. A. de S. Fundamentos de metodologia científica. 3 ed. São Paulo: Pearson Prentice Hall, 2007.

BERGAMINI, Cecília Whitaker; CODA, Roberto. Psicodinâmica da Vida Organizacional: Motivação e Liderança. 2. ed. São Paulo: Atlas, 1997.

CHIAVENATO, Idalberto. Gestão de Pessoas: O novo papel dos recursos humanos nas organizações. $1^{\text {a }}$ edição. Rio de Janeiro. Editora Campus, 1999.

CHIAVENATO, Idalberto. Introdução à Teoria Geral da Administração. 6. ed. Rio de Janeiro: Campus, 2000. 
GOLDENBERG, M. A arte de pesquisar. Rio de Janeiro: Record, 1997.

KAHAlE, Flávia. Pesquisando a Motivação: A Pesquisa de Clima Organizacional. Instituto MVC. Disponível em: < http://www.institutomvc.com.br/clima.htm. > Acesso em: 07 Out 2016.

LUZ. Modelos de Organogramas. Disponível em: <http://blog.luz.vc/o-que-e/modelos-deorganogramas/> Acesso em: 18 out. 2016.

OliveIRA, M. A. Pesquisas de Clima Interno nas Empresas: $O$ caso dos desconfiômetros avariados. São Paulo: Nobel, 1995.

PEROVANO, D.G. Manual de metodologia científica para a segurança pública e defesa social. Curitiba: Juruá, 2014.

SHAHIR, H. Y.; DANESHPAJOUH, S.; RAMSIN, R. Improvement strategies or agile processes: a SWOT analysis approach. In: Proc. of the SERA Conference, 2008. p. 221227.

STONER, James Arthur Finch; FREEMAN, R. Edward. Administração. 5. ed. Rio de Janeiro: LTC, 1999.

TEIXEIRA, I. T.; ROMANO, A. L.; EDMUNDO E. V. Estratégias De Operações No Setor De Serviços: O Caso Das Cooperativas De Saúde. São Paulo: Simpósio de Engenharia de Produção, XVIII, anais, UNESP, 2011.

TREASY. Matriz SWOT ou Matriz FOFA: utilizando a Análise SWOT para conhecer as cartas do jogo e aumentar as chances de vitória de sua empresa. Disponível em: $<$ https://www.treasy.com.br/blog/matriz-swot-analise-swot-matriz-fofa/> Acesso em: 18 out. 2016.

WEIHRICH, H. "The TOWS matrix: a tool for situational analysis". Journal of long range planning, v.15, n. 2, 1982. 